\title{
A Comparative Study on the Effect of the Voice of the Holy Quran and Arendeshine Music on the Anxiety of the Primiparous Women of the Natural Provisional Candidate
}

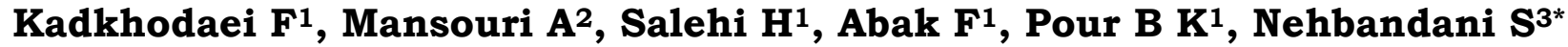 \\ ${ }^{1}$ Bsc student of Midwifery, Student Research Committee, Faculty of Nursing and Midwifery, Zabol \\ University of Medical Sciences, Zabol, Iran. \\ ${ }^{2}$ Msc in Nursing, Faculty of Nursing and Midwifery, Zabol University of Medical Sciences, Zabol, Iran. \\ ${ }^{3} \mathrm{Msc}$ in Midwifery, Faculty of Nursing and Midwifery, Zabol University of Medical Sciences, Zabol, \\ Iran.
}

\begin{abstract}
A B S T R A C T
Introduction and goal: Anxiety is the most common psychological reaction of pregnant women near childbirth and is a high prevalence in Iranian women. Nearly $50 \%$ of pregnant women report high levels of anxiety. The use of pharmaceutical methods to solve this problem has always led to problems and complications for patients. One of the non-pharmacological methods of music therapy. Therefore, the present study was conducted to compare the effects of the Voice of the Holy Qur'an and Arendeshine music on the anxiety of nulliparous women of normal delivery.

Materials and Methods: The study population consisted of all pregnant women referred to the maternity hospital of Amiralmounin Hospital in Zabol city. The sample consisted of 54 female candidates of normal delivery, selected by convenience sampling and randomly divided into two groups. The data collection instrument was Spielberger's Standard Anxiety Inventory. At first, the questionnaire was completed by patients. Then, in the first intervention group Arend Stein, and in the second intervention group, the voice of the Quran was broadcast for 45 minutes and immediately after that the questionnaire was completed again. SPSS software version 22 was used to analyze the data.

Findings: Findings showed that there was no significant difference between the mean of anxiety scores in the music group and the Qur'an before the intervention $(\mathrm{p}=0.11)$. But after the intervention, this difference was significant $(\mathrm{p}=0.02)$. Also, there was no significant difference between the mean scores of hidden anxiety in the two groups before the intervention $(p=$ $0.21)$. But after the intervention, this difference was significant $(\mathrm{p}=0.04)$.

Discussion and conclusion: According to the results of this study, it can be concluded that the Qur'anic verse can be used as a non-pharmacological method in the treatment of anxiety in women who are candidates for delivery. Hence, employees are advised to use this method in conjunction with routine care.
\end{abstract}

Key words: Quranic vocal, music, anxiety, nulliparous women, natural birth

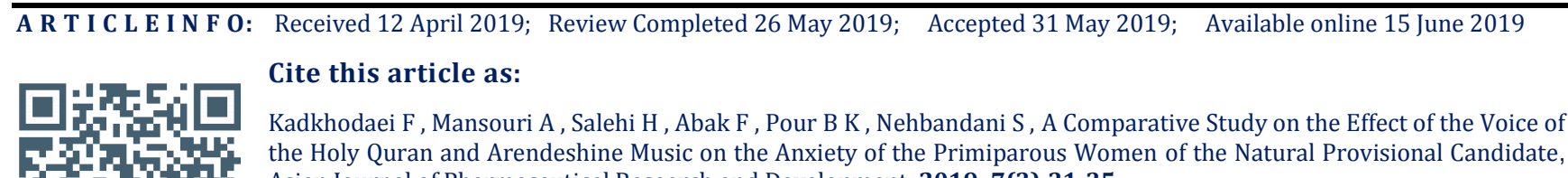
the Holy Quran and Arendeshine Music on the Anxiety of the Primiparous Women of the Natural Provisional Candidate, Asian Journal of Pharmaceutical Research and Development. 2019; 7(3):31-35 DOI: http://dx.doi.org/10.22270/ajprd.v7i3.510

*Address for Correspondence:

Sanaz Nehbandani, Zabol University of Medical Sciences, Zabol, Iran.

\section{INTRODUCTION:}

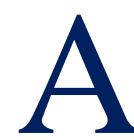
nxiety is a vague and unpleasant feeling of anxiety and is associated with symptoms such as tiredness, restlessness, palpitations, dizziness, and shortness of breath ${ }^{1-3}$. Anxiety is the most common psychological reaction of pregnant women near the birth ISSN: 2320-4850 and is high in Iranian women, so that $93 \%$ of pregnant women are afraid of childbirth and nearly $50 \%$ report high levels of anxiety ${ }^{4-6}$. In the anxiety pathology, there are cases of genetic, environmental, psychological, social and biological factors ${ }^{7}$. 
Anxiety has always been considered as a disruptive factor in the treatment of patients ${ }^{3}$. According to the control theory, there is a direct relationship between pain and anxiety, that is, women with higher anxiety experience more pain during labor. In fact, anxiety causes severe spasm of the pelvic floor and perineum and increases the severity of labor pain ${ }^{8}$. Fear of natural labor pain is one of the most common problems in primiparous women, and as one of the predictors of increasing maternal desire for cesarean delivery and increasing maternal and fetal complications ${ }^{9}$. Long-term anxiety leads to stimulation of the autonomic nervous system, which stimulates the smooth muscle contraction of the arteries, reduces the uterine-patchy blood flow, reduces the oxygen supply to the uterus, improves the abnormal pattern of the fetal heart rate and increases the likelihood of early delivery. Hormones such as catecholamines, cortisol, epinephrine and $\beta$-endorphins, which are released in response to anxiety, disrupt the development of cervical dilatation and also affect smooth muscle of the uterus and reduce the contractile power of the uterus and its efficacy in the process. Giving birth. All of these factors ultimately lead to prolonged labor and increase pain ${ }^{10}$.

Fear and anxiety are among the factors that play an important role in understanding the pain of labor and if they are resolved, their physical and mental relaxation is replaced and the severity of labor pain decreases ${ }^{11-12}$. Methods used to reduce anxiety in humans are divided into two categories: drug and non-pharmacological ${ }^{13}$. The use of pharmaceutical methods has always had problems and complications for patients; hence the necessity of using non-pharmacological and complementary methods as safe, healthier and less costly approaches ${ }^{14}$. Nonpharmaceutical methods include mental support for the mother, relaxation techniques, respiratory techniques, music therapies, bathtubs or showers and the use of complementary medicine ${ }^{4}$. While the mechanism of musical work is still unclear, it is believed that its use can be effective in reducing pain and anxiety because it has psychological and physiological effects, and it can relieve and distract patient from pain. It's all about It has also been proven that music affects painful stimuli and increases the secretion of endorphin ${ }^{16-15}$.

The use of sound in the treatment of diseases goes back to many years, as the Egyptian, Greek, Chinese, Hindi, and Roman inscriptions refer to music as a healing instrument ${ }^{17}$. Various studies have shown that music is effective in reducing anxiety after diagnostic treatments before surgery, pain and delivery anxiety. Music from the Qur'anic sound, as a pleasant mystical music with its special properties and melody and rhythm, can be an effective and safe intervention on patients' problems, including anxiety reduction. Research shows that Qur'anic voices are effective in reducing stress, irritability, loneliness, improving mood, and modulating emotions ${ }^{19}$.
It also reduces the acute phase pain of the first stage of labor and reduces anxiety before anesthesia induction and open heart surgery ${ }^{18}$. Arendestein is a German psychologist and composer, a scientist who has provided many music pieces for relaxation. Arend Sein's gentle and indomitable music is not traumatic or exciting. This music has rhythm and melodic turns, which smoothly monitors emotions and concerns in its uniform context, and does not induce a particular thrill ${ }^{20-21}$.

Considering the high level of pre-natal anxiety as well as its adverse effects on the individual and the baby, this study was conducted with the aim of comparing the effect of the voice of the Holy Quran and Arendeshine music on the anxiety of the nulliparous patients of the natural delivery candidate, The above method is based on the results of a scientific study to apply this method in the maternity ward as a pre-natal obstetric care.

\section{MATERIALS AND METHODS:}

The present study was an experimental study with pre-test and post-test that was designed and implemented in 1397. The study population consisted of all mothers who were referred to Amiralmounin Hospital in Zabol for delivery. The sample consisted of 54 pregnant women who were nominated for normal delivery, selected randomly and randomly divided into two groups. The inclusion criteria include prenatal women of normal delivery, abortion history, informed consent, score of 31 and above of the Spielberger Anxiety Inventory, no known known mental illness, no drug use, no participation in Stress and yoga control courses in the last 6 months were not a hearing loss and did not use sedative and analgesic drugs 3 hours before the intervention. There was also a lack of willingness to continue cooperation and the need for emergency cesarean section out of our study.

The data gathering tool in this study was divided into two parts: the first part of the questionnaire was personal characteristics such as age, education, income, sleep rate in the last 24 hours, the baby's sex, place of residence and duration of marriage. The second part of this tool was the Spielberger Standard Anxiety Inventory. The questionnaire consists of 40 questions, the first 20 of which are explicit anxiety and 20 of the second questions are about the hidden anxiety. The score for these questions is set as a Likert from score 1 (very low) to score 4 (very high).

To obtain a person's score in each of the two scales, the total scores of all twenty words of each scale are calculated. Therefore, the scores of each of the two state scales and the anxiety trap can range from 20 to 80 . The score is between 30-20 non-existent anxiety, 42-31 mild anxiety, 53-43 moderate anxiety and 54 and more severe anxiety. 
Validity and reliability of this questionnaire have been approved in Iran. In Rabiei et al., The validity of the questionnaire was verified and approved by ten nursing experts. Also, the reliability of this questionnaire was $87 \%$ in Tidman's research ${ }^{2}$. Also, in the study of Baghaei et al., The validity and reliability of the questionnaire were calculated and validated by $r=0.91$ and $0.825 \mathrm{alpha}^{3}$. At the beginning of the study and prior to the beginning of the study, the demographic information questionnaire and the Espill Berger questionnaire were completed by the patients. Then, each day of the week-other than Fridaycode was assigned (a total of 6 codes). Then, at the beginning of each week, randomly, 3 codes were assigned to the Qur'anic voice group and 3 codes for the Arrange Singles group, and on the specified days (according to the codes), only the Qur'anic verses or the music of Ardestin for intervention groups while taking care A routine was used. In the group of the Qur'anic verses, the epistle of Yusuf was played by the Trinity Master of the Faithful. It is worth noting that choosing verses and verses of the Qur'an was conducted by the opinion of one of the clerics of the university. Also in the band, Arend Stein's gentle and indomitable music was released from the album TopHis zum Entspannen Vol.1. For playback, an MP3 player was used with headphones. To prevent transmission of infection through headphones, headphones were disinfected after each use with alcohol cotton. Duration of intervention in both groups was 45 minutes, which was adapted from previous studies ${ }^{2}$. The researcher immediately completed the interview with the patients immediately after the interventions, and completed the collaboration with the participants to participate in the study. SPSS software version 22 and proper tests were used to analyze the data.

\section{Findings:}

Based on the findings, using Chi-square test and MannWhitney test, the two groups did not have a significant difference in terms of demographic characteristics ( $p>$ 0.05). (Table 1). Patients' demographic data revealed that the mean age of the participants in the Arndeshine group was 23/33 (6/71) and in the group of the Qur'anic verses 25.07 (4.92), and the two groups were completely identical in terms of age $(\mathrm{p}>0 / 05)$.

Table 1: Frequency Distribution and Comparison of Demographic Variables in Two Artists Steps and Quran Voices

\begin{tabular}{|c|c|c|c|c|c|c|}
\hline \multirow[t]{2}{*}{ variable } & \multirow{3}{*}{6} & \multicolumn{4}{|c|}{ Frequency } & \multirow[t]{3}{*}{ p-value } \\
\hline & & \multicolumn{2}{|c|}{ Music } & \multicolumn{2}{|c|}{ The Voice of the Qur'an } & \\
\hline & & Number & Percent & Number & Percent & \\
\hline \multirow[t]{2}{*}{ Baby gender } & Male & 16 & $59 / 3$ & $=15$ & $55 / 6$ & \multirow{2}{*}{$\begin{array}{c}* * \\
0 / 27\end{array}$} \\
\hline & Female & 11 & $45 / 7$ & 12 & $44 / 4$ & \\
\hline \multirow{3}{*}{$\begin{array}{l}\text { Sleep rate in the last } \\
24 \text { hours }\end{array}$} & Less than 5 hours & 14 & $51 / 9$ & 15 & $55 / 6$ & \multirow{3}{*}{$\begin{array}{c}* \\
0 / 797\end{array}$} \\
\hline & 5-8hours & 12 & $44 / 4$ & 11 & $40 / 7$ & \\
\hline & More than 8 hours & 1 & $3 / 7$ & 1 & $3 / 7$ & \\
\hline \multirow{5}{*}{$\begin{array}{l}\text { Income } \\
\text { (In USD) }\end{array}$} & Less than 30 & 12 & $44 / 4$ & 6 & $22 / 2$ & \multirow{5}{*}{$\begin{array}{c}* \\
0 / 215\end{array}$} \\
\hline & $30-60$ & 7 & $25 / 9$ & 10 & 37 & \\
\hline & $60-90$ & 2 & $7 / 4$ & 4 & $14 / 8$ & \\
\hline & $90-120$ & 1 & $3 / 7$ & 3 & $11 / 1$ & \\
\hline & More than 120 & 5 & $18 / 5$ & 4 & $14 / 8$ & \\
\hline \multirow[t]{2}{*}{ Accommodation } & City & 14 & $51 / 9$ & 13 & $48 / 1$ & \multirow{2}{*}{$\begin{array}{c}* * \\
1\end{array}$} \\
\hline & Village & 13 & $48 / 1$ & 14 & $51 / 9$ & \\
\hline \multirow{3}{*}{$\begin{array}{l}\text { Duration of marriage } \\
\text { (Per year) }\end{array}$} & $1-5$ & 22 & $81 / 5$ & 21 & $77 / 8$ & \multirow{3}{*}{$\begin{array}{c}* \\
0 / 702\end{array}$} \\
\hline & $6-10$ & 4 & $14 / 8$ & 4 & $14 / 8$ & \\
\hline & More than 11 & 1 & $3 / 7$ & 2 & $7 / 4$ & \\
\hline \multirow[t]{6}{*}{ Level of Education } & Illiterate & 5 & $18 / 5$ & 0 & 0 & \multirow{6}{*}{$\begin{array}{c}* \\
0 / 08\end{array}$} \\
\hline & Elementary & 3 & $11 / 1$ & 7 & $25 / 9$ & \\
\hline & After elementary & 5 & $18 / 5$ & 1 & $3 / 7$ & \\
\hline & Diploma & 12 & $44 / 4$ & 13 & $48 / 1$ & \\
\hline & Associate Degree & 0 & 0 & 0 & 0 & \\
\hline & Masters & 2 & $7 / 2$ & 6 & $22 / 2$ & \\
\hline
\end{tabular}

$\left(^{*}\right)$ Mann-Whitney U test, $\left(^{* *}\right)$ Chi- square test

The results showed that there was no significant difference between the mean of anxiety scores before and after the intervention in the music group $(p=0.20)$. But there was a significant difference between the mean of anxiety scores before and after intervention in the Quran's voice group $(\mathrm{p}=0.01)$. The findings showed that there was no significant difference between the mean of anxiety scores before and after intervention in the music group $(\mathrm{p}$ $=0.00$ ). Also, there was no significant difference between mean scores of hidden anxiety before and after 
intervention in Quran voice group ( $p=0.06)$. On the other hand, there was no significant difference between mean scores of apparent anxiety in the music group and the Qur'an before intervention $(\mathrm{p}=0.11)$. But after the intervention, this difference was significant $(p=0.02)$.
Also, there was no significant difference between the mean scores of hidden anxiety in the two groups before intervention $(\mathrm{p}=0.21)$. But after the intervention, this difference was significant $(\mathrm{p}=0.04)$. (Table 2).

Table 2: Comparison of mean of anxiety scores in two groups of music and vocal Quran

\begin{tabular}{|l|l|l|l|l|}
\hline \multicolumn{2}{|c|}{ variable } & Before intervention & After the intervention & \multicolumn{1}{c|}{ p-value } \\
\hline \multirow{2}{*}{ Obvious anxiety } & Music & $49 / 55 \pm 11 / 33$ & $47 / 07 \pm 11 / 45$ & $0 / 20$ \\
\cline { 2 - 5 } & Voice of the Qur'an & $49 / 85 \pm 9 / 13$ & $43 / 70 \pm 10 / 62$ & $0 / 01$ \\
\hline \multirow{2}{*}{ Hidden anxiety } & p-value & $0 / 11$ & $0 / 02$ & - \\
\hline & Music & $42 \pm 10 / 02$ & $42 \pm 9 / 44$ & 1 \\
\cline { 2 - 5 } & Voice of the Qur'an & $45 / 74 \pm 9 / 32$ & $43 / 70 \pm 9 / 05$ & $0 / 06$ \\
\hline
\end{tabular}

\section{DISCUSSION AND CONCLUSION:}

The results of this study showed that the voice of the Holy Qur'an and Ardestin music reduced the anxiety of the nulliparous patients of the natural delivery candidate, which is statistically significant in the Qur'anic voice group in the anxiety scale, and in other subscales in the two groups in terms of No statistical significance. This means that the Qur'an's voice in the anxiety section obviously improves anxiety, but in the hidden anxiety sector, according to the findings of this research, there is no significant statistical effect. Also, the use of music did not significantly affect any of the two aspects of anxiety. Also, this study shows that there is no significant difference between the two groups of music and the Quranic verses in terms of anxiety score before the intervention, but after the intervention, this difference is significant, which means that the effect of the Qur'an's voice versus music There is a greater effect on reducing anxiety in nulliparous women of normal delivery.

The influential effect of Quranic verses on the anxiety of mothers before delivery in apparent anxiety is consistent with the study by Samaeddini et al. ${ }^{12}$ and Sharifi et al. ${ }^{18}$. The results of these studies also indicate that the intervention was effective and significantly reduced the anxiety in pregnant mothers before delivery. In addition, Majidi et al. ${ }^{24}$, in their study, also confirmed the effect of Quranic verses on the anxiety level of their study group, which is consistent with the findings of our study. Other results of this study were to reduce the anxiety level in the Arendstein group and its insignificant statistically. The study of Mir Baqer et al. ${ }^{19}$ showed that using music significantly reduced the amount of anxiety in patients before general surgery, which is not consistent with the

\section{REFRENCES}

1. Sadri D E, Behbuei S, Mojarrad A. Role of Performance in the Stroop Test in Anticipation of Anxiety and Aggression in the Elderly in Ardabil. sija. 2018; 13(1):38-49.

2. Azizi M, Faghihzade S, Nematollahzade M, Lamyian M. The effect of counseling on anxiety after traumatic childbirth in nulliparous women; a single blind randomized clinical trial. J Kermanshah Univ Sci. 2010; 14(3):219-27. outcome of our study. Perhaps the reason for this difference in results is different environmental conditions. Because, unlike our study, Mirbacher and colleagues transmitted patients to a private room and intervened in a quiet environment. Accordingly, the provision of a suitable environment by Mir Baqer et al. May have increased the impact of this intervention on the research samples.

Based on the results of this study, the music and the Qur'an both reduce the anxiety of women in pre-natal period, but the effect of the Qur'anic voice, especially in the apparent anxiety sector, is due to the difference in their statistical significance on the reduction of anxiety. Is. This part of the findings is also consistent with the study by Sharifi et al. ${ }^{18}$. Considering the results of this study and its alignment with many studies in the field of anxiety, it is concluded that one can use the Qur'anic verse as a nonpharmacological method in the treatment of anxiety in women who are candidates for delivery. Hence, employees are advised to use this method in conjunction with routine care. It is also suggested to the authorities to incorporate non-pharmacological approaches such as sound therapy into their educational programs and pay more attention to this issue.

\section{ACKNOWLEDGMENTS:}

The present study is based on the research project conducted with the code of ethics IR.ZBMU.REC.1397.214. In this way, thanks to the support of the vice president of research in Zabol University of Medical Sciences, the management of the Amiralmomenin Hospital in Zabol city and all those who collaborated in this study are thanked and thanked.

3. Delaram M, Karami D A. The Effect of Accustomizing of Nulliparous Women with Personnel, Delivery Room and Equipments on Pre-Delivery Anxiety. Ijogi. 2011; 15(2):7-14.

4. Darooneh T, Ali A S B, Esmaeili S, Moattar F, Nasiri M, Delpak Y S, Ozgoli G. Effects of saffron capsule on labor anxiety in primiparous women: a clinical double-blind randomized controlled trial. IJOGI. 2017; 20(11):47-53. 
5. Walsh TC. Exploring the effect of hospital admission on contraction patterns and labour outcomes using women's perceptions of events. Midwifery. 2009; 25(3):242-52.

6. Rabiei Z, Jahanpour F, Azodi F, Azodi P. Effect of educational multimedia on anxiety before cesarean section. IJOGI. 2017; 20(5):24-9.

7. Mirzakhani K, Hejazinia Z, Golmakani N, Mirteimouri M, Ali Sardar M, Taghi SHakeri M. The effect of execution of exercise program with birth ball during pregnancy on anxiety rate in nulliparous women. IJOGI.2014; 17(117):8-16.

8. Tafazoli M, Zaremobini F, Mokhber N, Emami A. The effects of lavander oil inhalation on level of anxiety during first stage of labor in primigravida women. JFMH. 2011;12(48):720-6.

9. Akhlaghi F, Mokhber N, Shakeri MT, Shamsa F. Relation between depression, anxiety, self-esteem, marital satisfaction, demographical factor and maternal complications with fear of childbirth in nulliparous women. JFMH. 2012; 14(48):122-31.)

10. Delaram M, Soltanpour F. The Effect of Counselingin Third Trimester on Anxiety of Nulliparous Women at the Time of Admission for Labor.ZJRMS. 2012; 14(2):61-5.

11. Heydarpour S, Zare E, Mehrabi E, Heydarpour F, Kolivand M. Comparison of primiparas women perception of pain, fear and anxiety of vaginal delivery among Persian, Kurdish and Turkish women. JCRPS. 2015; 4(3):223-30.

12. Sahmeddini MA, Zamani Lari M, Rahimian MN, Danaei L, Beigi N, Habibi H. The Effect of Listening to the Quran on Serum Cortisol Levels and Anxiety in Primiparous Women during the First Stage of Labor. IJOGI. 2014; 17(99):1-7.

13. Heidari M, Shahbazi S. An Assessment of the Effect of Recitation of the Quran on Exam Anxiety in Nursing and Emergency Medicine Students. Strides Dev Med Educ. 2015; 12(1):56-63.

14. Najafi Ghezeljeh T, Salehzadeh H, Rafii F. Comparison of the effect of Swedish massage and preferred music intervention on anxiety in patients with chronic heart failure. ICNS. 2016; 5(1):36-43.
15. Koochakzai M, Mansouri A, Safarzadeh A, Navidian A. Effects of postnatal home-based education on primiparous women's perceived self-efficacy in neonatal care. Journal of Clinical and Diagnostic Research. 2018; 12(7):QC01-QC04

16. Surucu SG, Ozturk M, Vurgec BA, Alan S, Akbas M. The effect of music on pain and anxiety of women during labour on first time pregnancy: A study from Turkey. CTCP. 2018; 30(50):96-102.

17. Heidari M, Shahbazi S. Effect of Quran and Music on Anxiety in Patients during Endoscopy. Journal of Knowledge \& Health in Basic Med Sci. 2013;8(2):67-70.

18. Sharifi A, Alipour A, Baharloei S. Comparison of the Effect of Instrumental Music and Voices of Holy Quran on Anxiety of Woman before Cesarean. J Urmia Nurs Midwifery Fac. 2013; 10(6)

19. Mir B A N, Ranjbar N. Effects of Recitation of Holy Quran on Anxiety of Women before Cesarean Section: A Randomize Clinical Trial. Qom Univ Med Sci J. 2010; 4(1):15-9.

20. Khodabakhshi-K A, Zahmatkesh M, Barzeghar Khezri R. The effect of relaxation and instrumental music by Arnd Stein on quality of sleep and happiness among ageing women. Journal of Torbat Heydariyeh University of Medical Sciences. 2018; 5(4):46-53.

21. Fariba Y, Ali N, Seyed Mohammad N T, Sara S. Effect of instrumental music on pain intensity in patients with loss of consciousness in intensive care unit. Medical-Surgical Nursing Journal. 2016; 4(4):40-7.

22. Najafi ss. The Effect of Music Therapy on the Level of Anxiety and vital Signs in Patients undergoing trans-esophageal Echocardiography. JAP. 2018; 8(3):1-11.

23. Baghaei R, Alinejad V, Sharifi A. Impact of Cardiac Rehabilitation on Myocardial Infarction Patient's Anxiety. J Urmia Nurs Midwifery Fac. 2017; 14(12):1032-40.

24. Majidi S. Recitation Effect of Holy Quran on Anxiety of Patients before Undergoing Coronary Artery Angiography. jour guilan uni med sci. 2004; 13(49):61-67 